\title{
Evaluation of nicotine patch in pain control of patients undergoing laparoscopic cholecystectomy
}

\section{Avaliação do adesivo de nicotina no controle da dor em pacientes submetidos a colecistectomia videolaparoscópica}

Euclides Dias Martins Filho, TCBC-PE1; César Freire de Melo Vasconcelos²; Fernando de Santa Cruz Oliveira ${ }^{3}$; Adriano da Fonseca Pereira 4 ; Álvaro Antônio Bandeira Ferraz, tCBC-PE 1

\section{A B S T R A C T}

\begin{abstract}
Objective: to analyze the effects of nicotine patch on pain control, occurrence of nausea and its hemodynamic repercussions in laparoscopic cholecystectomy procedures. Methods: we conducted an analytical, prospective, randomized, triple-blinded, clinical study between January and July 2017. The sample consisted of 17 patients who underwent laparoscopic cholecystectomy for the treatment of cholelithiasis. Nine patients used nicotine patch, and eight, placebo patch. The studied variables were pain, nausea, patient satisfaction, blood pressure, heart rate, oximetry and morphine rescue. Results: taking into account the pain and nausea parameters, there was no statistically significant difference between the groups ( $p>0.05$ ). Also, the evaluation of rescue medication, both opioids and prokinetics, did not show any significant statistical difference between the groups. Among the hemodynamic parameters, there was only one statistically significant difference in the analysis of oxygen saturation and systolic blood pressure (SBP) six hours after surgery: the mean oxygen saturation was higher in the Test group $(97.89 \times 95.88)$ and the mean SBP was higher in the Control group $(123.89 \times 110.0)$. Conclusion: although pain levels were lower for nicotine within 24 hours, the action of nicotine and the need for rescue opioids in pain control were not statistically significant between the groups and at the time intervals studied. There was no clinical repercussion in the hemodynamic parameters.
\end{abstract}

Keywords: Nicotine. Pain. Cholecystectomy, Laparoscopic. Nausea.

\section{INTRODUCTION}

It is estimated that $10 \%$ to $15 \%$ of the American adult population, representing 20 to 25 million people, have or will have gallstones. In addition to health-related problems, cholelithiasis also causes high costs for public health, at around US\$ 6.2 million per year. Approximately 750,000 patients undergo cholecystectomy per year in the United States, and the number of surgical procedures has been increasing ${ }^{1}$. The use of non-steroidal anti-inflammatory drugs, analgesics and opioids is the main therapeutic modality applied to postoperative pain control. However, most of these drugs may manifest undesirable side effects such as gastritis, gastrointestinal bleeding, renal dysfunction and imbalance of cardiovascular homeostasis, especially when used for more than 48 hours $^{2,3}$.
To develop new therapeutic methods for postoperative pain control that can minimize antiinflammatory side effects, optimize analgesia and reduce excessive medication intake, some clinical research has attributed to nicotine a therapeutic adjunct in the regulation and control of the intensity of the acute inflammatory process through the modulation of nociceptive pathways located in the central nervous system ${ }^{4,5}$. The modulation of inflammatory pain through the mechanism of nicotine binding to a4B2 receptors has been described as an effective method for the control of traumatic disorders that affect peripheral nerve endings $s^{6,7}$.

Despite evidence of pain and inflammation control in soft tissue surgeries, there is a paucity of studies evaluating and measuring the efficacy of nicotine in the control of pain and inflammation in laparoscopic 
cholecystectomy (LC) with nicotine patch administered in the preoperative, as a vehicle for direct drug absorption and its systemic repercussions. The objective of this study was to evaluate the analgesic efficacy, satisfaction and the systemic repercussions resulting from the skin administration of nicotine patch in LC.

\section{METHODS}

We conducted a prospective, randomized, clinical study on an auxiliary tool in the control of postoperative pain in LC. We selected 58 volunteers from spontaneous demand from the Unified Health System (SUS) and attended the General Surgery Service of the Clinics Hospital of the Federal University of Pernambuco (HC-UFPE). All patients selected were eligible for cholecystectomy due to cholelithiasis. We included adult patients aged 17 to 80 years, classified as ASA I or II according to the American Society of Anesthesiology (ASA) criteria ${ }^{8}$, and excluded patients with suspected biliary tree neoplasia, acute cholecystitis, patients with chronic pain in regular use of analgesics, patients with untreated hypertension, ischemic heart disease, peripheral vascular disease, arrhythmias, diabetes, asthma, hyperthyroidism and pheochromocytoma. After application of the inclusion criteria, 30 patients remained.

All patients underwent LC. Prior to the procedure, we performed block-exchanged randomization with the purpose of defining which type of adhesive to be applied during the procedure. The use of draw to define the control had the objective to allow greater clarity in the differentiation between the Control and Test groups. To facilitate data collection and statistical treatment, we distributed the sample as follows: Control Group, consisting of patients treated with skin patch without an active principle, and Test Group, consisting of patients treated with a nicotine patch of $14 \mathrm{mg}$. The $14 \mathrm{mg}$ dose was based on the work of Hong et al. ${ }^{9}$ and its availability authorized by ANVISA for the Brazilian market.

We randomly sampled the adhesives with and without active principle, totaling 30 envelopes, enumerated and identified in a document kept by a researcher who was unaware of the content of the envelope, guaranteeing the triple-blindness of the research. Of the 30 patients selected, 13 entered the exclusion criteria, only 17 remaining. One hour before the procedure, the adhesive was placed in the left cervical region as described by Habib et al. ${ }^{10}$. The adhesive was covered with white tape, which did not influence the bioavailability of the drug, and was maintained for 24 hours, ensuring the research blinding and adhesive protection during the period of use.

In general intravenous anesthesia, we used of midazolam $(0.03 \mathrm{mg} / \mathrm{kg})$, fentanyl $(2 \mu \mathrm{g} / \mathrm{kg})$, remifentanil (0.1-1 $\mu \mathrm{g} / \mathrm{kg} / \mathrm{min}$ ), propofol ( $2 \mathrm{mg} / \mathrm{kg}$ for induction and 0.1 $0.2 \mathrm{mg} / \mathrm{kg} / \mathrm{min}$ for maintenance) and rocuronium $(0.5 \mathrm{mg} /$ $\mathrm{kg}$ ). Pneumoperitoneum was performed at a pressure of $12 \mathrm{mmHg}$. The neuromuscular blockade was reversed with neostigmine and immediate postoperative analgesia with morphine $(0.1 \mathrm{mg} / \mathrm{kg})$, Valdecoxib (Bextra ()$)(20 \mathrm{mg})$ and infusion with rupivacaine $20 \mathrm{ml}$ at $0.5 \%$ in the surgical ports. We monitored patients with cardioscopy, pulse oximetry and blood pressure measurement in the pre and intraoperative periods.

All patients received postoperative analgesia with Valdecoxib 20mg intravenously every 12 hours, the first dose during surgery, and paracetamol $750 \mathrm{mg}$ orally every six hours. The rescue medication was morphine, $0.1 \mathrm{mg} / \mathrm{kg}$, and the maximum dose was $10 \mathrm{mg} \mathrm{IV}$, every four hours, applied only when the pain was greater than $5 / 10$ in the visual analogue pain score (VAS). If the pain persisted $(V A S>5)$, after 30 minutes of morphine administration, an extra rescue dose was given, twice the dose of morphine given regularly $(0.2 \mathrm{mg} / \mathrm{kg})$, with a dose interval of 30 minutes, in a maximum of three doses, if necessary.

We controlled nausea with intravenous 8-mg ondansetron every eight hours in the first 24 hours post-surgery. If there was a need for antiemetic rescue, metoclopramide $10 \mathrm{mg}$ was given every eight hours. Rescue medication was applied when nausea was greater than $5 / 10$ in VAS.

The variables studied were pain, nausea, need for rescue drugs, patient satisfaction, blood pressure, heart rate and oxygen saturation. The pain and nausea parameters were studied as quantitative variables with the Visual Analogue Scale ${ }^{11}$ (VAS), a ruler format, with graded levels of pain and nausea. The VAS rulers were presented to the patients and they were asked to choose a number between 0 (mild pain/nausea) and 10 (unbearable pain/ 
nausea). These two variables were each analyzed in two distinct moments: six and 24 hours after surgery.

We used the modified Likert agreement scale to assess patient satisfaction ${ }^{12}$. We asked about the experience related to surgery ( 0 - bad; 1 - reasonable; 2 -good; 3 - very good; and 4 - excellent).

We evaluated systolic blood pressure (SBP), diastolic blood pressure (DBP), heart rate (HR) and oxygen saturation $\left(\mathrm{SpO}_{2}\right)$ during the procedure and at six and 24 hours postoperatively. The patients had their staging established in relation to blood pressure, according to the values determined by Chobanian et al. ${ }^{13}$.

This research was approved by the Ethics in Human Research Committee of the Health Sciences Center of the Federal University of Pernambuco, under CAAE number 56901416.9.0000.5208, in compliance with the recommendations expressed in Resolution 466/2012 of the National Health Council (CNS) on research involving human beings.

\section{RESULTS}

Table 1 shows the results regarding the characteristics of the sample. Only three men were part of the sample, two in the Control group and one in the Test group. The mean and median variables of age, surgical time and BMI were correspondingly higher in the Control group than in the Test group, but without significant differences between groups for any of the four variables analyzed ( $p>0.05)$.

Table 1. Research sample characteristics.

\begin{tabular}{|c|c|c|c|c|}
\hline \multirow{3}{*}{ Variable } & Control $(n=8)$ & Test $(n=9)$ & Total $(n=17)$ & \multirow{3}{*}{ p-value } \\
\hline & Mean \pm SD & Mean \pm SD & Mean \pm SD & \\
\hline & Median (P25; P75) & Median (P25; P75) & Median (P25; P75) & \\
\hline \multicolumn{5}{|l|}{ Gender: n (\%) } \\
\hline Male & $2(25.0)$ & $1(11.1)$ & $3(17.6)$ & $0.576^{(1)}$ \\
\hline Female & $6(75.0)$ & $8(88.9)$ & $14(82.6)$ & \\
\hline \multirow[t]{2}{*}{ Age (years) } & $39.75 \pm 15.65$ & $31.89 \pm 7.17$ & $35.59 \pm 12.22$ & $0.309^{(2)}$ \\
\hline & $39.50(24.50 ; 55.25)$ & $35.00(24.00 ; 38.50)$ & $36.00(24.00 ; 40.50)$ & \\
\hline \multirow[t]{2}{*}{ Surgical time (min) } & $106.88 \pm 24.63$ & $83.89 \pm 27.13$ & $94.71 \pm 27.89$ & $0.068^{(2)}$ \\
\hline & $120.00(86.25 ; 120.00)$ & $80.00(60.00 ; 115.00)$ & $110.00(60.00 ; 120.00)$ & \\
\hline \multirow[t]{2}{*}{ BMI $\left(\mathrm{kg} / \mathrm{m}^{2}\right)$} & $28.43 \pm 4.35$ & $26.24 \pm 4.73$ & $27.27 \pm 4.56$ & $0.200^{(2)}$ \\
\hline & $27.66(25.06 ; 30.03)$ & $24.25(22.90 ; 30.22)$ & $25.60(24.06 ; 29.94)$ & \\
\hline
\end{tabular}

(1) Fisher's exact test; (2) Mann-Whitney test.

Regarding the measurement of pain and postoperative nausea (Table 2) and the measurement of pain according to the group and the moment of the evaluation (Figure 1), we should note that the means and medians of pain were higher in the Control group than in the Test group. In the six-hour evaluation, the means were 1.75 and 2.11 in the Control and Test groups, and the medians were 0.50 and 2.00. In the 24-hour evaluation, the mean pain intensity was 1.25 and 0.89 , respectively, and the medians, 1.00 and 0.00 . The mean reduction between six hours and 24 hours was higher in the Test group than in the Control group $(1.22 \times 0.50)$, but without significant differences $(p>0.05)$. Also in table 2 , the means of nausea measurement in the six-hour evaluation in the Control and Test groups were 0.75 and 1.00, and at 24 hours, they were 0.00 and 0.22 , respectively; the medians were all nil. The means of reducing the intensity of nausea were 0.75 in the Control group and 0.78 in the Test group. There were no statistically significant differences between groups at any of the time points ( $p>0.05$ ). 
Table 2. Measurement of postoperative pain and nausea.

\begin{tabular}{|c|c|c|c|c|}
\hline \multirow{2}{*}{ Variable } & \multirow[b]{2}{*}{ Evaluation } & \multicolumn{2}{|c|}{ Groups } & \multirow[b]{2}{*}{ p-value } \\
\hline & & $\begin{array}{c}\text { Control } \\
\text { Mean } \pm \text { SD } \\
\text { Median (P25; P75) }\end{array}$ & $\begin{array}{c}\text { Test } \\
\text { Mean } \pm \text { SD } \\
\text { Median (P25; P75) }\end{array}$ & \\
\hline \multirow[t]{5}{*}{ Pain } & $6 h$ & $1.75 \pm 2.31$ & $2.11 \pm 2.15$ & $0.616^{(1)}$ \\
\hline & & $0.50(0.00 ; 3.75)$ & $2.00(0.00 ; 4.00)$ & \\
\hline & $24 h$ & $1.25 \pm 1.39$ & $0.89 \pm 1.45$ & $0.514^{(1)}$ \\
\hline & & $1.00(0.00 ; 2.75)$ & $0.00(0.00 ; 2.00)$ & \\
\hline & $p$-value & $0.500^{(2)}$ & $0.125^{(2)}$ & \\
\hline Mean absolute difference & $6 h-24 h$ & 0.50 & 1.22 & $0.501^{(1)}$ \\
\hline \multirow[t]{5}{*}{ Nausea } & $6 h$ & $2.12 \pm 0.75$ & $2.00 \pm 1.00$ & $0.718^{(1)}$ \\
\hline & & $0.00(0.00 ; 0.00)$ & $0.00(0.00 ; 2.50)$ & \\
\hline & $24 h$ & \pm 0.000 .00 & $0.22 \pm 0.67$ & $0.346^{(1)}$ \\
\hline & & $0.00(0.00 ; 0.00)$ & $0.00(0.00 ; 0.00)$ & \\
\hline & $p$-value & $1.000^{(2)}$ & $0.500^{(2)}$ & \\
\hline Mean absolute difference & $6 h-24 h$ & 0.75 & 0.78 & $0.876^{(1)}$ \\
\hline
\end{tabular}

(1) Mann-Whitney test; ${ }^{(2)}$ Wilcoxon test for paired data.

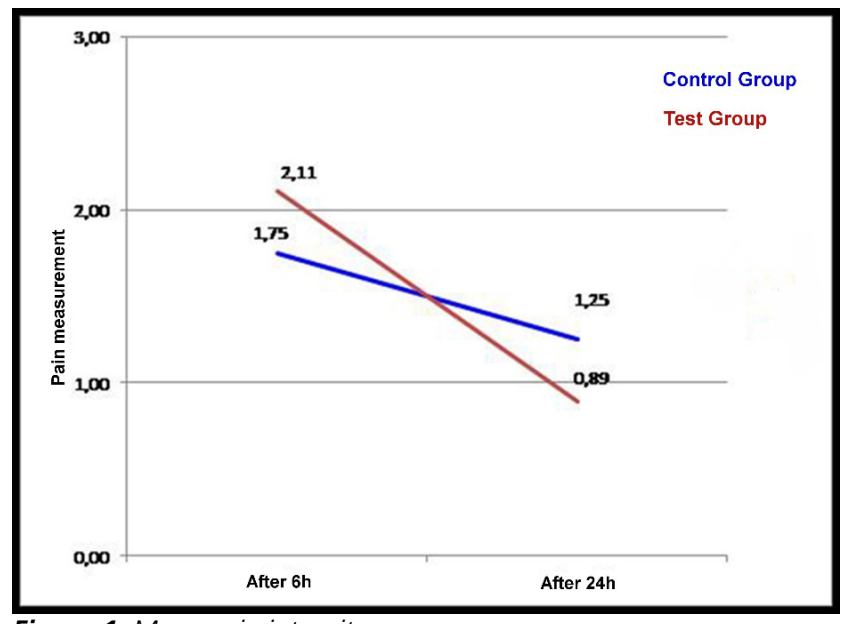

Table 3 presents the correlation coefficients between the pain data at six hours, 24 hours and the variation between six and 24 hours for age, surgical time and $\mathrm{BMI}$, according to the group and in total. The only statistically significant correlation other than zero $(p<0.05)$ occurred between age and pain value six hours after surgery, a negative (indicating an inverse relationship) and reasonably high correlation (-0.695). All correlations with BMI were negative.

Figure 1. Mean pain intensity.

Table 3. Spearman's correlation coefficients between pain and age, time of surgery and BMI.

\begin{tabular}{|c|c|c|c|c|}
\hline Evaluation & Group & $\begin{array}{l}\text { Age } \\
r_{s}(p)\end{array}$ & Surgical time (min) & BMI $\left(\mathrm{kg} / \mathrm{m}^{2}\right)$ \\
\hline \multirow[t]{3}{*}{$6 \mathrm{~h}$} & Control & $0.304(0.454)$ & $0.158(0.709)$ & $-0.457(0.255)$ \\
\hline & Test & $-0.695(0.038 *)$ & $0.258(0.503)$ & $-0.265(0.491)$ \\
\hline & Total & $-0082(0.755)$ & $0.096(0.713)$ & $-0.356(0.161)$ \\
\hline \multirow[t]{3}{*}{$24 h$} & Control & $0.257(0.539)$ & $0.539(0.168)$ & $-0.129(0.762)$ \\
\hline & Test & $-0.540(0.133)$ & $0.142(0.715)$ & $-0.299(0.435)$ \\
\hline & Total & $0.072(0.784)$ & $0.316(0.216)$ & $-0.213(0.412)$ \\
\hline \multirow[t]{3}{*}{ Variation $6 \mathrm{~h}-24 \mathrm{~h}$} & Control & $0.241(0.565)$ & $-0.108(0.799)$ & $-0.660(0.075)$ \\
\hline & Test & $-0.341(0.369)$ & $0.192(0.620)$ & $-0.092(0.814)$ \\
\hline & Total & $-0.032(0.903)$ & $-0.054(0.836)$ & $-0.274(0.287)$ \\
\hline
\end{tabular}


In the study of the correlation between pain variation between the two evaluation moments, the highest value occurred with the $\mathrm{BMI}$ in the Control group $(-0.660)$, but none was statistically different from zero $(p>0.05)$.

Due to the presence of only three male patients in the study, two in the Control group and one in the Test group, there were no comparisons of pain by gender and the reason for not categorizing the data of age, surgical time and BMI were the small number of patients in each group.

Only one patient in each group needed the rescue medication within up to six hours, and between six and 24 hours two patients made use of it in the Test group, there being no significant statistical difference between the groups in each evaluation nor between the evaluations in each group (Table 4). The need for the use of metoclopramide was recorded in one patient in the Control group at the evaluation within up to six hours and in one patient in the Test group between six and 24 hours. We found no relevant differences between the groups at each time of medication or between the evaluations in each group.

Table 4. Assessment of rescue medication according to group and time.

\begin{tabular}{|c|c|c|c|}
\hline \multirow[b]{2}{*}{ Rescue medication/Time } & \multicolumn{2}{|c|}{ Groups } & \multirow[b]{2}{*}{ p-value } \\
\hline & $\begin{array}{c}\text { Control } \\
\mathrm{n}(\%)\end{array}$ & $\begin{array}{c}\text { Test } \\
\mathrm{n}(\%)\end{array}$ & \\
\hline Total Group & $8(100.0)$ & $9(100.0)$ & \\
\hline \multicolumn{4}{|l|}{ Morphine } \\
\hline Up to 6 hours & & & $1.000^{(1)}$ \\
\hline Yes & $1(12.5)$ & $1(11.1)$ & \\
\hline No & $7(87.5)$ & $8(88.9)$ & \\
\hline Between 6 and 24 hours & & & $0.471^{(1)}$ \\
\hline Yes & - & $2(22.2)$ & \\
\hline No & $8(100.0)$ & $7(77.8)$ & \\
\hline$p$-value & $* *$ & $1.000^{(2)}$ & \\
\hline \multicolumn{4}{|l|}{ Metoclopramide } \\
\hline 6 hours & & & $0.471^{(1)}$ \\
\hline Yes & $1(12.5)$ & - & \\
\hline No & $7(87.5)$ & $9(100.0)$ & \\
\hline 24 hours & & & $1.000^{(1)}$ \\
\hline Yes & - & $1(11.1)$ & \\
\hline No & $8(100.0)$ & $8(88.9)$ & \\
\hline Value of $p$ & $\star \star$ & $\star \star$ & \\
\hline
\end{tabular}

**Unable to determine because of the absence of categories; ${ }^{(1)}$ Fisher's exact test; ${ }^{(2)}$ McNemmar test.

Regarding the hemodynamic parameters (Table 5), we found that the only significant differences between groups occurred in oxygen saturation and SBP in the six-hour evaluation. These variables emphasize that the mean oxygen saturation at the six-hour evaluation was higher in the Test group than in the Control group
(97.89 $\times 95.88)$, and the mean SBP was higher in the Control group than in the Test group (123.89 $\times 110.0$ ). For the mentioned situations, we should note that in the Control group the means of oxygen saturation ranged from 95.88 (after six hours) to 98.00 (during surgery) and in the Test group, from 97.56 (after 24 hours) to 98.56 
(pre and during surgery). The mean SBP in the Test group surgery (109.44), and ranged from 118.89 to 122.44 in was higher after six hours (123.89) and lower during the other evaluations.

Table 5. Hemodynamic changes according to group and evaluation.

\begin{tabular}{|c|c|c|c|c|}
\hline \multirow{3}{*}{ Variable } & \multicolumn{4}{|c|}{ Groups } \\
\hline & Evaluation & Control & Test & p-value \\
\hline & & Mean \pm SD (Median) & Mean \pm SD (Median) & \\
\hline \multirow[t]{5}{*}{ Heart rate } & Pre & $80.13 \pm 20.41(77.50)$ & $85.67 \pm 13.66(88.00)$ & $0.516^{(1)}$ \\
\hline & Intra & $83.88 \pm 10.18(81.50)$ & $84.44 \pm 13.26(85.00)$ & $0.923^{(1)}$ \\
\hline & $6 \mathrm{~h}$ & $88.75 \pm 11.63(88.00)$ & $86.11 \pm 13.67(85.00)$ & $0.676^{(1)}$ \\
\hline & $24 h$ & $86.25 \pm 6.23(87.00)$ & $83.44 \pm 10.03(87.00)$ & $0.495^{(3)}$ \\
\hline & p-value & $0.520^{(4)}$ & $0.921^{(4)}$ & \\
\hline \multirow[t]{2}{*}{$\begin{array}{l}\text { Mean absolute } \\
\text { difference }\end{array}$} & Pre-6h & 8.63 & 0.44 & $0.398^{(1)}$ \\
\hline & Pre-24h & 6.13 & -2.22 & $0.328^{(1)}$ \\
\hline \multirow[t]{5}{*}{ Saturation of the ${ }_{2}$} & Pre & $97.75 \pm 1.49(97.00)^{(\mathrm{A})}$ & $98.56 \pm 0.73(99.00)^{(\mathrm{AB})}$ & $0.162^{(2)}$ \\
\hline & Intra & $98.00 \pm 1.51(97.50)^{(\mathrm{A})}$ & $98.56 \pm 0.73(98.00)^{(\mathrm{AB})}$ & $0.320^{(2)}$ \\
\hline & $6 h$ & $95.88 \pm 1.64(96.00)^{(\mathrm{B})}$ & $97.89 \pm 0.33(98.00)^{(\mathrm{BC})}$ & $0.002^{(2) *}$ \\
\hline & $24 h$ & $97.13 \pm 0.99(97.00)^{(\mathrm{A})}$ & $97.56 \pm 1.01(98.00)^{(\mathrm{C})}$ & $0.327^{(2)}$ \\
\hline & $p$-value & $0.017^{(5) *}$ & $0.029(5) *$ & \\
\hline \multirow[t]{2}{*}{$\begin{array}{l}\text { Mean absolute } \\
\text { difference }\end{array}$} & Pre-6h & 1.88 & 0.67 & $0.102^{(2)}$ \\
\hline & Pre-24h & 0.63 & 1.00 & $0.589^{(2)}$ \\
\hline \multirow[t]{5}{*}{ SBP } & Pre & $121.00 \pm 16.63(115.00)$ & $122.44 \pm 11.29(120.00)^{(\mathrm{A})}$ & $0.514^{(2)}$ \\
\hline & Intra & $114.88 \pm 9.34(115.00)$ & $109.44 \pm 13.79(100.00)^{(B)}$ & $0.301^{(2)}$ \\
\hline & $6 h$ & $110.00 \pm 10.69(110.00)$ & $123.89 \pm 12.69(120.00)^{(A)}$ & $0.022(2) *$ \\
\hline & $24 h$ & $111.25 \pm 9.91(110.00)$ & $118.89 \pm 11.67(120.00)^{(\mathrm{AB})}$ & $0.171^{(2)}$ \\
\hline & $p$-value & $0.358^{(5)}$ & $0.022^{(5) *}$ & \\
\hline \multirow[t]{2}{*}{$\begin{array}{l}\text { Mean absolute } \\
\text { difference }\end{array}$} & Pre-6h & 11.00 & -1.44 & $0.086^{(2)}$ \\
\hline & Pre-24h & 9.75 & 3.56 & $0.433^{(2)}$ \\
\hline \multirow[t]{5}{*}{ DBP } & Pre & $79.13 \pm 11.29(77.50)$ & $79.78 \pm 8.01(80.00)$ & $0.806^{(2)}$ \\
\hline & Intra & $78.00 \pm 10.03(80.00)$ & $70.00 \pm 12.99(70.00)$ & $0.216^{(2)}$ \\
\hline & $6 \mathrm{~h}$ & $75.63 \pm 9.80(70.00)$ & $78.89 \pm 10.54(80.00)$ & $0.442^{(2)}$ \\
\hline & $24 h$ & $7.04 \pm 73.13(70.00)$ & $78.33 \pm 10.00(80.00)$ & $0.184^{(2)}$ \\
\hline & p-value & $0.300^{(5)}$ & $0.289^{(5)}$ & \\
\hline \multirow[t]{2}{*}{$\begin{array}{l}\text { Mean absolute } \\
\text { difference }\end{array}$} & Pre-6h & 3.50 & 0.89 & $0.846^{(1)}$ \\
\hline & Pre-24h & 6.00 & 1.44 & $0.404^{(1)}$ \\
\hline
\end{tabular}

*Significant difference to the level of 5.0\%; (1)Student's $t$ test with equal variances; ${ }^{\left({ }^{2}\right)}$ Mann-Whitney test; ${ }^{(3)} B y$ Student's $t$ test with unequal variances; ${ }^{(4)}$ F-test (ANOVA) for repeated measures; ${ }^{(5)}$ Friedman test with comparisons of the referenced test. Note: If all the letters in the parentheses are distinct, there is significant difference between the corresponding times by paired comparisons of that test. 
The mean and median values of patient satisfaction were both equal to 3.00 in each of the groups, with no significant difference between them ( $p>0.05)$, as presented in table 6 .

Table 6. Patients' satisfaction according to group.

\begin{tabular}{|c|c|c|}
\hline \multicolumn{3}{|c|}{ Groups } \\
\hline Control & Test & p-value \\
\hline Mean \pm SD (Median) & Mean \pm SD (Median) & \\
\hline $3.00 \pm 0.76(3.00)$ & $3.00 \pm 0.87(3.00)$ & $1.000^{(1)}$ \\
\hline
\end{tabular}

\section{DISCUSSION}

We were careful to standardize the type of disease and the surgical technique, which resulted in a homogeneous sample. The objective was to modulate the inflammatory process and homogenize patients and technique to avoid or minimize interference in the results obtained. Thus, we excluded 13 patients who presented exclusion criteria, and the main one was acute cholecystitis.

The patients' ages ranged from 17 to 59 years, with an average of 35. The Test group consisted of eight women and one man, and the Control group, six women and two men, with no statistical significance in the assessment of pain between the groups. Another variable noted was surgical time. We considered that it would be the time interval between the moment of the incision and the end of the suture. In this study, we observed an average time of 94 minutes, ranging from 55 to 120 . The mean time of the Control group was $106.88 \mathrm{~min} \pm$ 24.63, and of the Test group, 89.89min \pm 27.00 , with no statistical significance. Although the surgical time was above the average described in the literature, it is noteworthy that the surgical procedures were carried out by the resident doctor in the second training year. It should be noted that a greater or lesser surgical time may influence the outcome of postoperative pain, which was not seen in our study considering hypothesis testing ${ }^{14}$.

The data obtained by measuring pain with the VAS $(n=17)$ pointed to a higher level of pain intensity in interventions with nicotine after six hours of intervention. In the Test group, the mean pain was higher than in the Control group, and was not statistically significant for this time interval. There is therefore the possibility of interference of intraoperative anesthetic drugs in the first measurement, since the interval between the anesthetic act and the measurement was very short. In the evaluation after 24 hours, we observed statistically lower levels of pain in surgeries with administration of the active principle. When pain control was evaluated in patients in the Test group between six and 24 hours, we evidenced an expressive reduction in mean pain, although not statistically significant. We also evaluated the effect of nicotine in patients who did not use morphine $(n=15)$ as rescue drug. There was no statistically significant difference between the groups for pain, however, there was more pain in the Test group at six hours. For the 24 hour time interval, the Test group was smaller. When analyzing the two situations for the 24-hour evaluation time, the pain scores are lower for the group that used nicotine. In a double-blind, randomized, placebo-controlled clinical trial, patients who underwent prior gynecological surgery of $3 \mathrm{mg}$ nicotine reported lower pain scores compared with placebo. When the VAS was filled in the first 24 hours postoperatively, the mean pain was $5.3 \pm 1.6$ for nicotine versus $7.6 \pm 1.4$ for placebo $(p<0.001)^{15}$. Habib et $a{ }^{10}{ }^{10}$, in a double-blind study with two cutaneous patch groups, one test (7mg nicotine) and the other placebo, showed that the nicotine group had significantly lower pain and, consequently, lower need for morphine in 24 hours when compared with the placebo group ( $p=0.002$ ). These data corroborate our postoperative pain findings in the 24-hour measurement.

In this study, only one patient in each group required rescue morphine in the first six hours, there being no significant difference. After six to 24 hours 
postoperatively, only two patients in the Test group required rescue morphine, also without significant difference between groups. We suggest that nicotine was not effective in reducing the rescue drug. A study using nicotine in pain control in thoracic surgery found VAS scores significantly lower in the Test group compared with the placebo group over the first 48 hours $^{16}$. The number of rescue opioids was significantly higher in the placebo group compared with the Test group. We did not identify the reason for this negative result in relation to nicotine for our experiment. We also observed that, for up to six hours, both patients who required rescue opioids were female and had a prolonged surgical time. Regarding intraoperative drug use, both of them used opioids, which was not able to interfere with this result. For the period between six and 24 hours, we observed two patients in the female Test group, with prolonged, similar surgical times, and one patient who needed morphine in the two times studied, ie, only three patients required rescue morphine. In addition, preoperative pain was zero in these patients. Flood and Daniel ${ }^{15}$ obtained significant statistical results regarding the consumption of postoperative morphine in the group that received nicotine. The authors reported a 50\% reduction in postoperative morphine consumption for the group that received the active principle when compared with placebo $(p<0.05)$, which did not occur in this study. The results of the previous work are also in agreement with the data obtained from a systematic review with metaanalysis that investigated the effectiveness of nicotine in the control of postoperative pain in procedures under general anesthesia. The review authors concluded that preoperative nicotine administration was associated with a significant reduction in the need for opioid use in the first 24 hours compared with the Control (placebo), with a mean reduction in consumption of $-4.85 \mathrm{mg}$ of morphine, respecting the $95 \%$ confidence interval ${ }^{17}$. The results of this study are discordant, since the intrinsic response of the patients to the perioperative drugs used, as well as the small sample number, were responsible for differing with the literature data.

The literature mentions that the route of nicotine administration may be nasal or dermal. Yagoubian et al. ${ }^{14}$ studied the nasal instillation of $3 \mathrm{mg}$ of preoperative nicotine and observed that it is able to significantly reduce pain scores in oral surgery when compared with the use of placebo. In the group of patients who received the active principle, the mean pain was $1.6( \pm 0.5)$ with nicotine and $2.9( \pm 0.5)$ for the placebo group, but there was no statistical difference in the amount of rescue analgesics consumed postoperatively. In this study, after 24 hours, there was a tendency of pain scores in favor of nicotine, though without statistical difference between groups. Our selected route of administration was cutaneous, yet the results were similar. It would therefore be necessary to perform an experimental model similar to that nasal nicotine study, since adhesive formulations have a slower absorption pharmacokinetics relative to spray instillations. The plasma peak for nicotine spray is $4.7(3.2) \mathrm{ng} / \mathrm{ml}$, obtained ten minutes after instillation, which may contribute to a higher dose of the circulating active ingredient in a short period of time and, consequently, increase the likelihood of undesirable effects and decrease the duration of pharmacological action $^{14,15,18}$.

The use of adhesive nicotine has the pharmacokinetic property of allowing slower and gradual absorption of the active principle for a period of up to 24 hours. The plasma peak happens after four hours of administration, coinciding with the period of greater pain intensity and contributing to a greater comfort of the patient and less need for supplemental analgesic in the postoperative period 9,19,20. Considering the aforementioned plasma peak, a priori, the patients in this study's Test group should not present higher pain scores. Although patients received the same drugs in the intraoperative period, the intrinsic response may have been responsible for the result. Though there were no significant results between groups, we observed a lower pain intensity for the nicotine group in 24 hours. These results corroborate the literature and are important in the evaluation because they suffer less interference of intraoperative drugs. In future research, we suggest to collect data on pain measurement in periods of six, 12 and 24 hours. Different drug doses and distinct absorption pathways interfere with the therapeutic response and side effects ${ }^{21}$.

In relation to nicotine, one of the main adverse 
reactions mentioned in the literature is nausea, and this effect can be observed in patients who received $14 \mathrm{mg}$ in adhesive or $3 \mathrm{mg}$ by nasal instillation ${ }^{14}$. Despite the positive effects in controlling the inflammatory and painful process, the administration of nicotine can induce a sensation of nausea. A meta-analysis involving patients from randomized studies for nicotine replacement therapy has observed that acute exposure to the drug may cause this sensation ${ }^{20}$. In this study, the quantification of nausea assessed the patients' experience of this undesirable effect at the six and 24 hour intervals after the surgical procedure, respecting the numerical intervals between 0 (absence of nausea) and 10 (maximum nausea). Mean values of 1.00 and 0.22 were obtained in patients who received nicotine patch in the first six and 24 hours, respectively. The Control group displayed an average value of 0.75 and 0 at six and 24 hours, respectively, equivalent to the literature citations, which mention the possibility of this effect after the use of nicotine. Although related to the "light" description in VAS at the $14 \mathrm{mg}$ dose, other studies revealed higher nausea scores with significantly lower nicotine concentrations. When analyzing patients from the Control and Test groups that did not use morphine as a rescue analgesic, we observed scores of zero nausea for the Control group and 0.57 (six hours) and 0.29 (24 hours) for the Test group. Although there is no statistical significance, it is evident the tendency of nausea in patients who use adhesive nicotine.

Habib et al. ${ }^{10}$ administered $4 \mathrm{mg}$ of ondansetron in 44 patients who received $7 \mathrm{mg}$ of nicotine patch prior to general surgery. They observed that, despite the prophylactic use, the highest scores for nausea were present in patients who received nicotine, but the difference between the placebo and nicotine groups was not statistically significant ( $p>0.05)$. In this study, we used a fixed regimen of $8 \mathrm{mg}$ ondansetron every eight hours, and rescue metoclopramide. In the Control group, one patient needed rescue drug for nausea after six hours of the procedure, and in the Test group, one patient needed it after 24 hours. When analyzing the patients that needed the rescue drug, we observed that patients who used salvage morphine also needed a rescue antiemetic, which did not occur in patients who did not use the opioid. It is noteworthy that all patients used regular ondansetron and this may have prevented higher values in the nausea score. We could not conclude whether the side effect of nicotine (nausea) is indeed related, since all patients received ondansetron as standard medication and there was no significant difference between the groups.

Flood et al. ${ }^{15}$ used a drug protocol for general anesthesia that included the administration of fentanyl, isoflurane, vecuronium and a prophylactic dose of $4 \mathrm{mg}$ of ondansetron for patients exposed to $7 \mathrm{mg}$ of nicotine. The results obtained confirm that the prophylactic dose of $4 \mathrm{mg}$ of ondansetron is ineffective for the control of nausea in patients receiving nicotine. There was also no statistical difference in antiemetic consumption between the placebo group and the nicotine one $(p=0.29)$. In another study, Hong et al. ${ }^{9}$ systematized the application of a single dose of $4 \mathrm{mg}$ ondansetron to patients undergoing abdominal surgery who used placebo or nicotine patch to control pain. In patients who received $10 \mathrm{mg}$ nicotine patches, the antiemetic dose was $7 \mathrm{mg}$, and for those given $15 \mathrm{mg}$ nicotine a $9 \mathrm{mg}$ dose of ondansetron was used. The authors observed that the amount of nausea in the placebo group was similar to the group receiving $4 \mathrm{mg}$ of ondansetron. Patients who received $10 \mathrm{mg}$ or $15 \mathrm{mg}$ of nicotine presented similar scores in relation to nausea with the use of $7 \mathrm{mg}$ and $9 \mathrm{mg}$ of ondansetron, respectively ( $p>0.05)$. Based on these data, the patients in this study could benefit from the previous dose of $9 \mathrm{mg}$ of ondansetron, aimed at suppressing the levels of nausea found with $14 \mathrm{mg}$ patches. Czarnetzki et al. ${ }^{22}$ studied 90 patients and found a 24-hour cumulative incidence of nausea of $42.2 \%$ with nicotine and $40.0 \%$ with placebo $(p=0.83)$ and vomiting of $31.1 \%$ with nicotine and $28.9 \%$ with placebo $(p=0.81)$. On the other hand, lonescu et al..$^{23}$ state that nicotine is able to prevent nausea. This study was an isolated one compared with the rest of the consulted literature. Therefore, we decided to administer $8 \mathrm{mg}$ of ondansetron to nausea, avoiding undesirable effects in the postoperative period and in the early recovery.

Nicotine is a direct, broad-spectrum agonist of central nicotinic receptors, which mediate sympathetic transmission in the ganglia, and may interfere with 
hemodynamics, for example, with increased heart rate, blood pressure and oximetry ${ }^{24}$. On the other hand, Greenland et al. ${ }^{20}$ performed a meta-analysis that included 3,752 patients submitted to nicotine replacement therapy, with no difference in the prevalence of cardiovascular diseases. The data obtained from this study, through the measurement of the systemic arterial pressure after six hours of the intervention, pointed to a higher systolic and diastolic pressure level in the interventions with nicotine. In the Test group, mean SBP was $123.89 \pm 12.69$, and DBP, $78.89 \pm 10.54$, and in the interventions of the Control group, mean SBP was $110.00 \pm 10.69$, and DBP, $75.63 \pm 9.80$, being statistically significant for SBP $(p=0.022)$ and not significant for DBP $(p=0.216)$.

In the 24-hour evaluation in the Test group, mean SBP was $118.89 \pm 11.67$ and DBP $78.33 \pm 10.00$, and in the interventions of the Control group, mean SBP was $111.25 \pm 9.91$ and PAD $73.13 \pm 7.04$, not being statistically significant for both evaluations. Although all values were slightly higher in the Test group, there were no clinical repercussions in the two groups studied. For Chobanian et al. ${ }^{13}$, the normality patterns for systolic blood pressure would be lower than $120 \mathrm{mmHg}$, and they observed in the Test group, for six hours, that the SBP values were higher than this established value, without, however, clinical repercussions. It is known that several factors may be related to changes in blood pressure, such as surgical stress, postoperative pain, among others that may influence the adrenergic response and raise blood pressure. Nonetheless, we could not indicate another factor that justified a higher blood pressure in the Test group other than the nicotine patch.

In another study, Flood and Daniel ${ }^{15}$ analyzed 20 female patients with mean age of 45 years, ASA I and II, who underwent uterine surgery. They observed that systolic blood pressure was lower in the group that received nicotine $(105.00 \pm 3.00$ versus $122.00 \pm$ 3.00; $p<0.001)$, but there was no difference in diastolic blood pressure and heart rate. The authors emphasize that these values may have suffered interference by anesthetic medication, since they used isoflurane, and this medication may decrease autonomic stimulation and, consequently, blood pressure.

It is noteworthy that most of the research that evaluates the role of nicotine in pain control is performed under general anesthesia. Since some drugs used by this method act competitively with nicotinic receptors, the results obtained may present biases, because this interaction may minimize the expected effects of pain control, especially with the use of isoflurane ${ }^{25}$. To avoid the influence of general inhalation anesthetics, all the patients in this study were submitted to pure intravenous general anesthesia, and the results were satisfactory for pain control in both groups. We should note that we used different drugs to perform general anesthesia, possibly introducing confounding factors or interfering in the efficacy of nicotine in pain control. For this reason, we methodologically chosen evaluation times of six and 24 hours, so that there was a lower influence of drugs administered intraoperatively.

The role of nicotine in pain modulation presents well-defined evidence in gynecological and urological surgery, but protocols of doses or concentrations have not yet been established that allow better postoperative comfort with smaller amounts of undesirable effects. In this study, we found that the level of patient satisfaction and postoperative comfort with the use of nicotine patches with $14 \mathrm{mg}$ was equal to the Control group $(p=1)$. We believe that the degree of satisfaction is not related only to pain, but also to other aspects such as hosting, waiting time to perform the surgical procedure, the result of the intervention, etc.

New studies should be conducted to address knowledge gaps in relation to nicotine use. Key points that may avoid biases are listed: probabilistic sample, greater intraoperative drug control, analysis of the effects of the active principle at other time intervals, dose adjustment by BMI, and standardization of operative time. 


\title{
R E S U M O
}

\begin{abstract}
Objetivo: analisar os efeitos do adesivo de nicotina sobre o controle da dor, ocorrência de náuseas e suas repercussões hemodinâmicas em cirurgias de colecistectomia videolaparoscópica. Métodos: estudo analítico, do tipo ensaio clínico, prospectivo, randomizado e triplo-cego realizado entre janeiro e julho de 2017. A amostra foi composta de 17 pacientes em pós-operatório de colecistectomia videolaparoscópica para tratamento de colelitíase. Nove pacientes fizeram uso do adesivo com nicotina e oito de adesivo placebo. As variáveis estudadas foram: dor, náusea, satisfação do paciente, pressão arterial, frequência cardíaca, oximetria e resgate de morfina. Resultados: levando em consideração os parâmetros dor e náuseas, não houve diferença estatisticamente significativa entre os grupos ( $p>0,05)$. Ainda, a avaliação da medicação de resgate, tanto opioide como procinéticos, também não evidenciou diferença estatística relevante entre os grupos. Dentre os parâmetros hemodinâmicos, só houve diferença estatística nas análises da saturação de oxigênio e da pressão arterial sistólica (PAS) seis horas após a cirurgia: a média da saturação de oxigênio foi maior no grupo Teste $(97,89$ × 95,88) e a média da PAS foi maior no grupo Controle $(123,89 \times 110,0)$. Conclusão: apesar dos níveis de dor terem sido menores para nicotina no intervalo de 24 horas, a ação da nicotina e a necessidade de opioide de resgate no controle da dor não foram estatisticamente significantes entre os grupos e intervalos de tempo estudados. Não houve repercussão clínica nos parâmetros hemodinâmicos.
\end{abstract}

Descritores: Nicotina. Dor. Colecistectomia Laparoscópica. Náusea.

\section{REFERENCES}

1. Stinton LM, Shaffer EA. Epidemiology of gallbladder disease: cholelithiasis and cancer. Gut Liver. 2012;6(2):172-87.

2. Ong CK, Lirk P, Seymour RA, Jenkins BJ. The efficacy of preemptive analgesia for acute postoperative pain management: a meta-analysis. Anesth Analg. 2005;100(3):757-73.

3. Kazancioglu HO, Kurklu E, Ezirganli S. Effects of ozone therapy on pain, swelling, and trismus following third molar surgery. Int J Oral Maxillofac Surg. 2014;43(5):644-8.

4. Benowitz NL. Nicotine and postoperative management of pain. Anesth Analg. 2009;107(3):739-41.

5. Rowley TJ, McKinstry A, Greenidge E, Smith W, Flood P. Antinociceptive and anti-inflammatory effects of choline in a mouse model of postoperative pain. $\mathrm{Br} J$ Anaesth. 2010;105(2):201-7.

6. Nakamura $M$, Jang IS. Presynaptic nicotinic acetylcholine receptors enhance GABAergic synaptic transmission in rat periaqueductal gray neurons. Eur J Pharmacol. 2010;640(1-3):178-84.

7. Fukada T, Iwakiri H, Ozaki M. A randomised doubleblind crossover trial of the potential analgesic effect of a transdermal nicotine patch in non-smokers based on objective and subjective assessment. Eur J
Anaesthesiol. 2011;28(8):592-6.

8. Schwam SJ, Gold MI, Craythorne UWG. The ASA physical status classification: a revision. Anesthes. 1982;57(3):A439.

9. Hong D, Conell-Price J, Chang S, Flood P. Transdermal nicotine patch for postoperative pain management: a pilot dose-ranging study. Anesth Analg. 2008;7(3):1005-10.

10. Habib AS, White WD, El Gasim MA, Saleh G, Polascik TJ, Moul JW, et al. Transdermal nicotine for analgesia after radical retropubic prostatectomy. Anesth Analg. 2008;107(3):999-1004.

11. Faiz KW. [VAS--visual analog scale]. Tidsskr Nor Legeforen. 2014;134(3):323. Nowegian.

12. Likert R. A technique for the measurement of attitudes. Arch Psychol. 1932;22(140):1-55.

13. Chobanian AV, Bakris GL, Black HR, Cushman WC, Green LA, Izzo JL Jr, Jones DW, Materson BJ, Oparil S, Wright JT Jr, Roccella EJ; National Heart, Lung, and Blood Institute Joint National Committee on Prevention, Detection, Evaluation, and Treatment of High Blood Pressure; National High Blood Pressure Education Program Coordinating Committee. The seventh report of the Joint National Committee on Prevention, Detection, Evaluation, and Treatment of high blood pressure: the JNC 7 report. JAMA. 2003;289(19):2560-72. 
14. Yagoubian B, Akkara J, Afzali P, Alfi DM, Olson L, Conell-Price J, et al. Nicotine nasal spray as an adjuvant analgesic for third molar surgery. J Oral Maxillofac Surg. 2011;69(5):1316-9.

15. Flood $P$, Daniel $D$. Intranasal nicotine for postoperative pain treatment. Anesthesiology. 2004;101(6):141721.

16. Nagy HI, Elkadi HW. Transdermal nicotine patch as adjunctive analgesic modality to thoracic epidural analgesia for post-thoracotomy pain. Egypt J Cardiothorac Anesth. 2014;8(2):75-82.

17. Mishriky BM, Habib AS. Nicotine for postoperative analgesia: a systematic review and meta-analysis. Anesth Analg. 2014;119(2):268-75.

18. Fortuna A, Alves G, Serralheiro A, Sousa J, Falcão A. Intranasal delivery of systemic-acting drugs: smallmolecules and biomacromolecules. Eur J Pharm Biopharm. 2014;88(1):8-27.

19. Olson LC, Hong D, Conell-Price JS, Cheng S, Flood P. A transdermal nicotine patch is not effective for postoperative pain management in smokers: a pilot dose-ranging study. Anesth Analg. 2009;109(6):1987-9.

20. Greenland S, Satterfield MH, Lanes SF. A metaanalysis to assess the incidence of adverse effects associated with the transdermal nicotine patch. Drug Saf. 1998;18(4):297-308.

21. Pastore MN, Kalia YN, Horstmann M, Roberts MS. Transdermal patches: history, development and pharmacology. Br J Pharmacol. 2015;172(9):2179209.

22. Czarnetzki C, Schiffer E, Lysakowski C, Haller G, Bertrand $D$, Tramèr MR. Transcutaneous nicotine does not prevent postoperative nausea and vomiting: a randomized controlled trial. Br J Clin Pharmacol. 2011;71(3):383-90.

23. Ionescu D, Badescu C, Acalovschi I. Nicotine patch for the prevention of postoperativee nausea and vomiting: a prospective randomised trial. Clin Drug Investig. 2007;27(8):559-64.

24. Yoshikawa H, Kurokawa M, Ozaki N, Nara K, Atou $K$, Takada $E$, et al. Nicotine inhibits the production of proinflammatory mediators in human monocytes by suppression of I-kappaB phosphorylation and nuclear factor-kappaB transcriptional activity through nicotinic acetylcholine receptor A7. Clin Exp Immunol. 2006;146(1):116-23.

25. Flood P, Ramirez-Latorre J, Role L. Alpha 4 beta 2 neuronal nicotinic acetylcholine receptors in the central nervous system are inhibited by isoflurane and propofol, but alpha 7-type nicotinic acetylcholine receptors are unaffected. Anesthesiology. 1997;86(4):859-65.

Received in: 18/01/2018

Accepted for publication: 22/03/2018

Conflict of interest: none.

Source of funding: none.

\section{Mailing address:}

Fernando de Santa Cruz Oliveira

E-mail: f.santacruzoliveira@gmail.com /

vasconceloscfm@gmail.com

\section{(cc) BY}

